\title{
Desenhe seu trajeto: visualização de dados sobre o uso do espaço e a participação de usuários no projeto de sinalização da Universidade Federal do Espírito Santo
}

\author{
Draw your path: data visualization about the space \\ usage and user participation on the design of the signage \\ system for Universidade Federal do Espírito Santo
}

Mauro Pinheiro, Ricardo Esteves Gomes, Matheus Rocha de Souza Ramos

design centrado no usuário; visualização de dados; sinalização; mapas

\begin{abstract}
O artigo discute a aplicação de métodos de Design Centrado no Usuário no desenvolvimento do projeto de sinalização da Universidade Federal do Espírito Santo. Descreve-se a metodologia utilizada na pesquisa com a comunidade da Ufes, que possibilitou identificar terminologias e marcos de referência utilizados pelos próprios usuários na descrição do campus da universidade. Destaca-se a aplicação de técnicas de visualização de dados para a identificação de padrões de comportamento do público frequentador do espaço. A partir da representação gráfica de trajetos descritos pelos usuários, foi criado um «mapa de trajetos» que permitiu perceber os trajetos com maior tráfego de pessoas, sendo possível distinguir rotas principais e secundárias. Essas informações serviram de base para a estratégia que orientou a localização dos elementos de sinalização a serem implantados no campus da universidade.
\end{abstract}

user-centered design; data visualization; signage; maps;
The paper discusses the use of User-Centered Design methods in the development of a new signage system for Universidade Federal do Espírito Santo. The methodology used in the research within the university community is described. The methods used enabled the identification of terminologies and landmarks used by the community to describe the campus. Data visualization techniques were used for identifying public behavior patterns about how the space was used. Graphical representations of user's paths have generated $a$ «path map» which allowed to vizualize the paths with greater traffic, being possible to distinguish main and secondary routes. This information formed the basis for the strategy that guided the location of signaling elements to be deployed on the university campus. 


\section{Introdução}

Nos últimos anos observamos no campo do Design a popularização dos métodos de projeto reunidos sob a denominação «Design Centrado no Usuário». Para Abras, Maloney-Krichmar e Preece (2004):

'Design Centrado no Usuário' (DCU) é um termo amplo para descrever os processos de projeto em que os usuários finais influenciam o modo como um projeto toma forma. É ao mesmo tempo uma filosofia e uma ampla variedade de métodos. Há diversas formas através das quais os usuários são envolvidos no DCU, mas o conceito fundamental é que os usuários se integram no processo de uma maneira ou de outra. (Abras, Maloney-Krichmar e Preece, 2004, tradução nossa)

Essa abordagem conteitual-metodológica, embora tenha se destacado principalmente em projetos que envolvem o desenvolvimento de dispositivos e sistemas digitais (Winograd e Kuhn, 1996; Garret, 2011), tem alcançado uma abrangência crescente dentro do campo do design (Chaves, Bittencourt \& Taralli, 2013), especialmente após a popularização de métodos englobados sob a alcunha de Design Thinking (BROWN, 2010; Vianna et al, 2012). No Brasil, desde os anos 80, também é conhecida a metodologia de projeto denominada Design em Parceria, desenvolvida por professores da PUC-Rio (Dal Bianco, 2007). Independente das especificidades dos métodos utilizados ou das denominações de tais abordagens metodológicas, destaca-se uma característica em comum: a participação dos usuários em diferentes etapas do processo projetual.

Neste artigo descrevemos o método utilizado para identificar os caminhos percorridos pela comunidade universitária no campus Goiabeiras da Universidade Federal do Espírito Santo, localizado na cidade de Vitória (ES). A pesquisa foi realizada pela equipe do ProDesign Ufes, Laboratório de Projetos em Design vinculado ao Departamento de Desenho Industrial da mesma universidade, que desenvolve os projetos de sinalização dos quatro campi da Ufes. Durante a etapa de levantamento de dados, foram realizadas pesquisas com os usuários, com aplicação de questionários mistos, com perguntas fechadas e abertas. Esses questionários ajudaram a identificar terminologias e marcos de referência utilizados pelas pessoas para descrever o campus. Durante o processo, os usuários foram convidados a desenhar o trajeto que realizavam com maior frequência. Esses dados foram trabalhados e geraram «mapas de trajeto», indicando as regiões com maior tráfego de usuários por qualquer meio: fosse a pé, por automóvel, por motocicleta ou por bicicleta, considerando também o uso híbrido desses diferentes modos de deslocamento. Além disso, os mapas auxiliaram na identificação dos principais pontos de entrada no campus, bem como as rotas 
principais e secundárias, naturalmente instituídas na cultura local. Dessa forma foi possível estabelecer diretrizes para a localização dos elementos de sinalização ao longo do campus, baseado no uso que a própria comunidade faz do espaço.

A seguir descrevemos o contexto do projeto, bem como explicitamos os métodos utilizados e resultados obtidos.

\section{Contexto do projeto}

O projeto de sinalização do campus Goiabeiras da Universidade Federal do Espírito Santo vem sendo desenvolvido pelo ProDesign Ufes. Contando atualmente com dois coordenadores, professores do Departamento de Desenho Industrial, e quinze alunos do curso de design, o ProDesign Ufes surgiu como um programa de extensão universitária, a partir da demanda da administração central da Ufes, no sentido de desenvolver projetos de sinalização para os seus quatro campi: os de Goiabeiras e Maruípe localizados em Vitória, o campus de São Mateus e o campus de Alegre.

O campus de Goiabeiras é o principal e mais antigo da Ufes. Fundado em 1954, localiza-se na capital do Espírito Santo, Vitória, e concentra a maior parte dos cursos de graduação, mestrado e doutorado, seus centros de ensino, laboratórios de pesquisa e projetos de extensão. Nele também estão os principais setores administrativos da universidade, como a Reitoria, as Pró-reitorias e as Secretarias. Além disso, o campus ainda abriga uma creche infantil, uma escola de ensino médio, Restaurante Universitário, uma área de cultura e lazer com uma galeria de arte, um café, um cinema e um teatro, além da Biblioteca Central e diversas bibliotecas setoriais. Possui ginásio de esportes, parque aquático, academia de ginástica e musculação, área para prática de arco e flecha e outros equipamentos esportivos. Conta com uma Rádio Universitária, Centro de Línguas, agências bancárias, Observatório Astronômico e Planetário. O campus tem uma área total de 1.567.545,00 $\mathrm{m}^{2}$, e é cercado por um manguezal mantido sob proteção ambiental.

Com uma vasta oferta de serviços à população, estima-se que no campus de Goiabeiras circulem diariamente cerca de 22 mil pessoas, entre alunos, professores, servidores e visitantes.

Com 65 anos de existência, o campus teve um crescimento orgânico, apresentando grande diversidade arquitetônico-urbanística. A ocupação do espaço ao longo dos anos se deu de maneira desigual, ora apresentando grande densidade de prédios e serviços, ora apresentando grandes áreas vazias. Para a comunidade acadêmica é comum a delimitação de regiões do campus de acordo com seus centros de ensino (Centro de Artes, Centro de Educação, Centro de Educação Física e Desportos, Centro de Ciências Exatas, Centro de Ciências Humanas e Naturais, Centro de Ciências Jurídicas e Econômicas, Centro Tecnológico) ${ }^{1}$. De modo semelhante, na cultura

1 Outros campi da Ufes abrigam o Centro de Ciências da Saúde e o Centro de Ciências Agrárias. 
local, ocorrem agrupamentos de diferentes centros por setores, como no caso da região dos «ICs» (sigla proveniente da nomenclatura 'Ilha Cercada”, original das primeiras edificações construídas naquele local), englobando três diferentes centros (região vermelha, Figura 1). Outro caso onde isso ocorre é a região dos «Cemunis» (região verde, Figura 1), também originária da nomenclatura dos primeiros prédios construídos, agrupando o Centro de Artes e o curso de Psicologia, pertencente administrativamente a outro centro de ensino. Embora haja exceções, na maioria dos casos os departamentos, laboratórios e grupos de pesquisa dos respectivos centros de ensino situam-se próximos, em uma mesma região do campus.

Figura 1 Mapa do campus de Goiabeiras. Divisões por cor (atualmente não existentes) como possível estratégia de agrupamentos visuais por setores. Observa-se como há uma maior aglomeração de prédios nos setores vermelho, azul claro e azul escuro, enquanto os setores verde e laranja contam com maiores áreas vazias na ocupação do terreno.

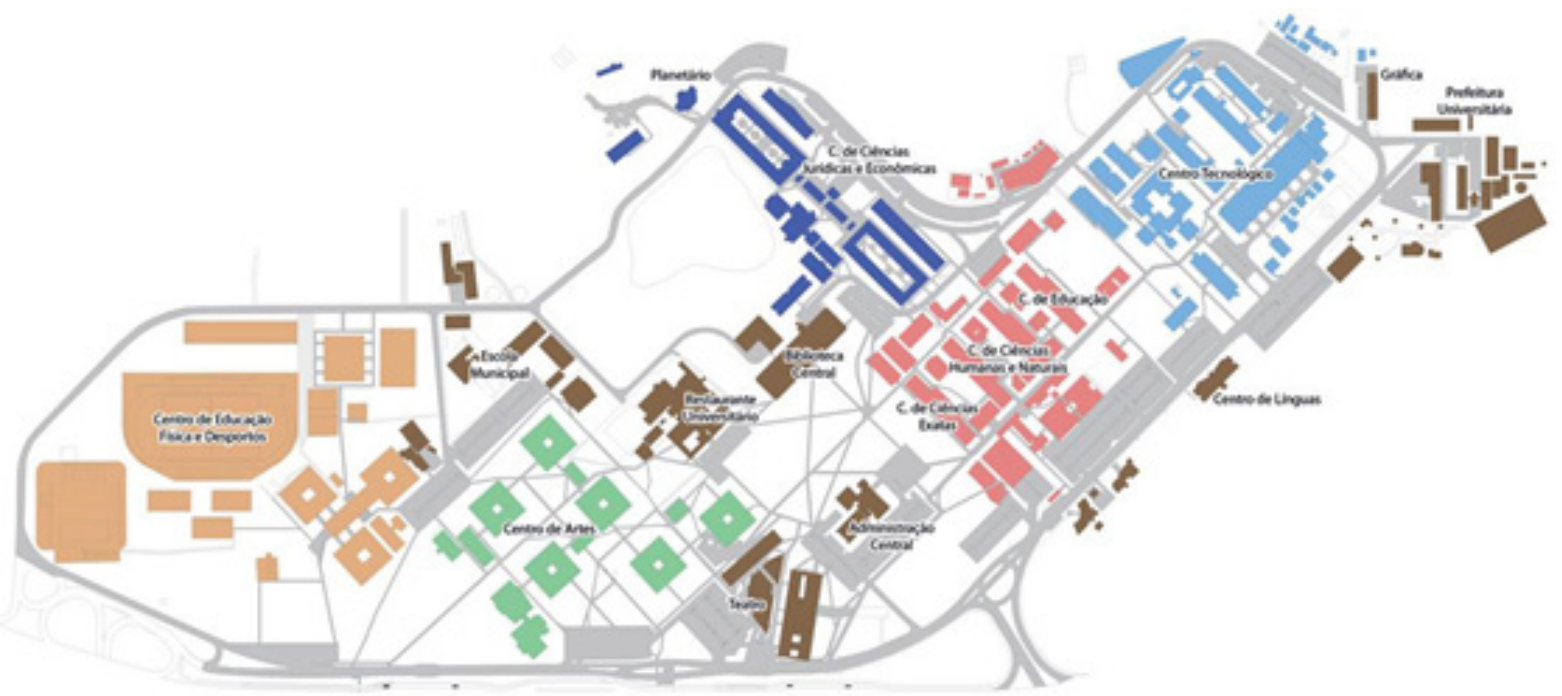

O campus de Goiabeiras conta, até o presente, com um sistema de sinalização que se encontra em grande parte desatualizado e parcialmente destruído, tanto pela ação do tempo quanto por vandalismo. É comum observar a apropriação dos suportes pela própria comunidade universitária, que se aproveita dos elementos existentes para colar cartazes diversos, estabelecendo organicamente espaços de comunicação efêmera. 
Figura 2 Totens de concreto, placas identificadoras e cartazes. É possível observar o estado de deterioração de grande parte das peças ao longo do campus, bem como a apropriação desordenada pela comunidade.
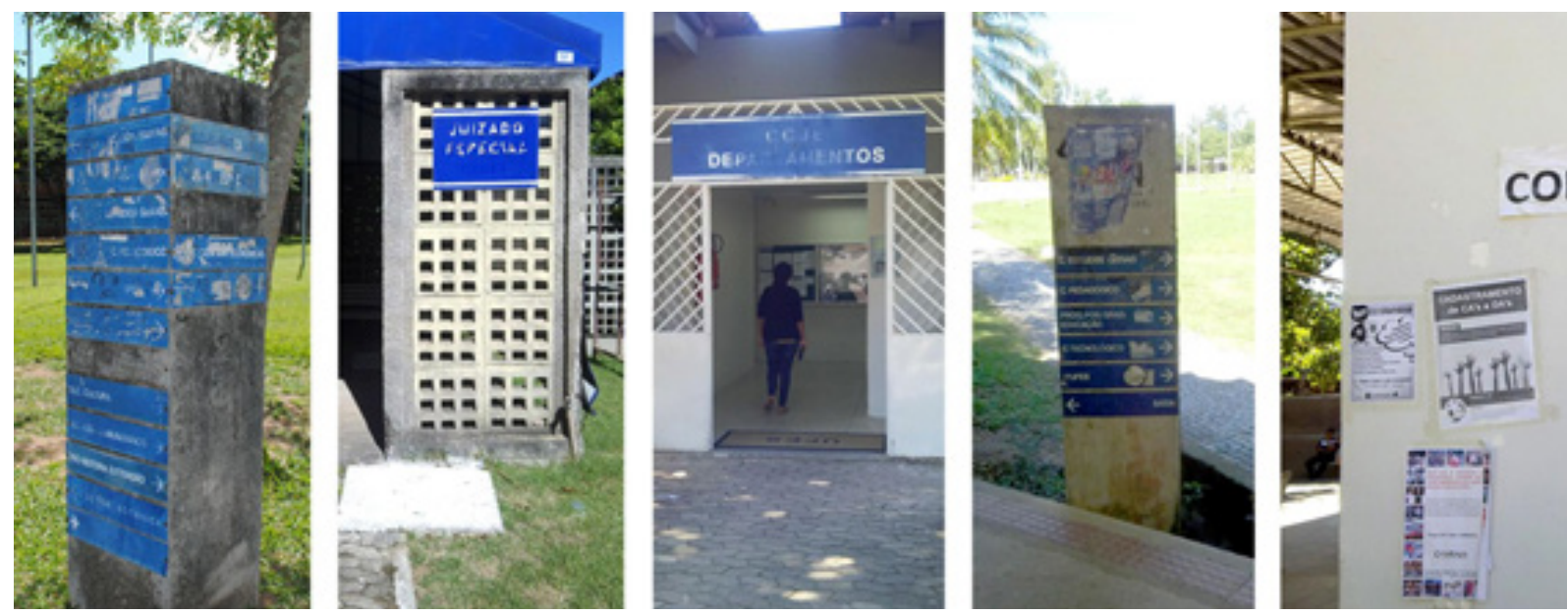

É notável também o crescimento da universidade nos últimos anos, a partir de investimentos do governo federal através do Programa de Apoio a Planos de Reestruturação e Expansão das Universidades Federais (Reuni), bem como de parcerias entre laboratórios de pesquisa da instituição e empresas privadas. A criação de novos prédios e ocupação de espaços outrora vazios, aliado à diversidade de serviços dispersos em um campus de grande extensão, tornaram ainda mais urgente a revisão da sinalização atual. Dessa forma, o ProDesign Ufes iniciou em 2013 o projeto Sistema de Sinalização para a Ufes.

\section{Métodos utilizados}

Desde o início do projeto, buscou-se garantir o envolvimento da população-alvo no processo. Experiências anteriores já apontavam a importância da aplicação de métodos de pesquisa com usuários em projetos de sinalização (Pinheiro et al, 2006). Apesar de todos os membros da equipe serem professores e alunos da instituição - portanto familiarizados com o campus - buscou-se identificar como a comunidade da Ufes entende o espaço, como se refere a ele, bem como que caminhos eram utilizados com mais frequência. A intenção foi identificar as terminologias utilizadas, quais os marcos significativos dentro do campus - informações que poderiam servir para estabelecer estratégias de comunicação e posicionamento de elementos de sinalização posteriormente. Foram então elaboradas duas ferramentas para o levantamento de dados: o questionário e o mapa de trajetos. Descreveremos o questionário brevemente, uma vez que o foco deste artigo é o mapa de trajetos. 


\section{Questionário}

Foi elaborado um questionário misto com quatorze perguntas: oito perguntas com respostas fechadas e seis perguntas com respostas abertas. As primeiras perguntas buscavam traçar o perfil do entrevistado, com informações como: o tipo de vínculo com a universidade (se era aluno, professor, servidor ou visitante); frequência com que visita o campus; há quanto tempo frequenta o campus; e meio de transporte utilizado para chegar à Ufes.

O questionário buscou também identificar quais nomenclaturas e termos eram usados pela população. Por exemplo, o campus da universidade conta com seis entradas. Duas dessas entradas são compartilhadas entre automóveis e pedestres, sendo as únicas que recebem uma denominação formal (Norte e Sul). As entradas exclusivamente para pedestres não contam com qualquer nomenclatura oficial. Dessa forma, no questionário, pediu-se que o participante indicasse qual portão de acesso utilizava corriqueiramente. Mais adiante, o questionário apresentava um mapa com as entradas numeradas, e o participante era solicitado a responder como se referia a cada uma delas.

Existe uma cultura institucionalizada na universidade de utilizar siglas e abreviações para identificação dos seus centros de ensino, edificações e serviços. Dentre alguns exemplos: CAR, CLC, CT, CCJE, CCHN, CEFD, CE, PU, PRPPG, IC, ED, Setpes, Cemuni. A lista é grande! Nossa hipótese era que essas siglas poderiam soar incompreensíveis e serem de difícil memorização para pessoas que não utilizavam tais locais com frequência. Para aferir essa questão, o questionário trazia uma lista com treze siglas usadas no campus, e o participante deveria responder quais ele conhecia. Logo em seguida, uma lista de nomes de centros de ensino, órgãos e serviços era apresentada, e novamente o participante deveria indicar quais eram de seu conhecimento. Importante destacar que os questionários foram aplicados pela equipe do ProDesign Ufes, de modo que os participantes não tinham acesso direto ao material impresso. Dessa forma, buscou-se evitar que os usuários associassem imageticamente as siglas aos nomes por extenso que viriam logo a seguir na página do questionário aplicado.

Foram realizados testes iniciais, após os quais o questionário sofreu pequenas alterações na sequência de perguntas. Uma vez consolidado o modelo, aplicou-se o questionário durante 50 dias não sequenciais, abrangendo 501 pessoas, que frequentavam o campus em diferentes horários ao longo do dia. Os usuários foram abordados em diversos pontos do campus e por diferentes pessoas da equipe do ProDesign Ufes. A média de tempo gasta na aplicação de um questionário era de aproximadamente 25 minutos. 


\section{A imagem do Campus pelos seus próprios usuários}

O uso de diagramas para evidenciar padrões de comportamento é bem representado no caso clássico do médico John Snow (Tufte, 1997), que em 1854 investigava os motivos do surto de cólera na região central da cidade de Londres. A crença na época era que a doença devia-se à poluição e à circulação de ar deficiente nas moradias da população afetada. Ao representar com pontos em um mapa da região os casos de cólera notificados, Snow percebeu uma grande concentração na área próxima à bomba d'água pública da rua Broad. Formulou então a hipótese que a água seria a forma de contágio, e não o ar. Sua hipótese foi confirmada com a análise das fontes de abastecimento das bombas d'água, que mostraram que a captação dava-se a partir de pontos altamente poluídos do rio Thames. Desse modo, a visualização de dados contribuiu decisivamente para a identificação do problema e erradicação posterior da epidemia.

Figura 3 Mapa de John Snow, mostrando a incidência de casos de cólera na região central de Londres. Cada ponto representa um caso notificado. A concentração de pontos junto à bomba d'água evidencia indícios de uma relação causal.

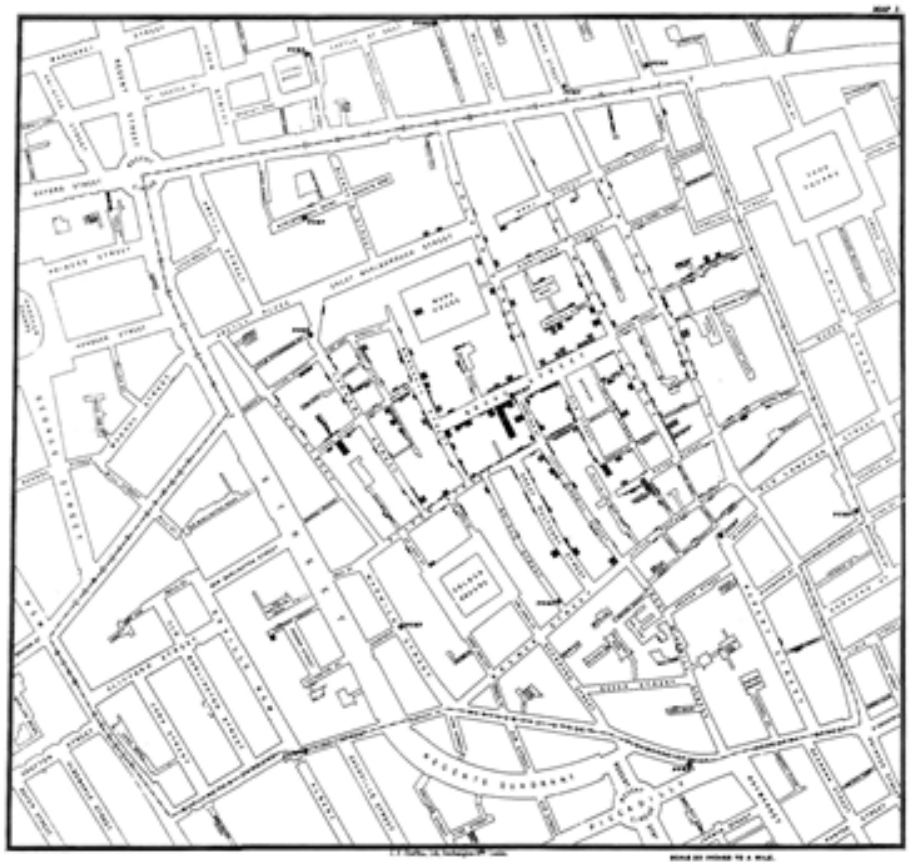

Um caso contemporâneo e relevante sobre a geração de significados a partir da visualização de dados é o do designer português Pedro Miguel Cruz (Cruz, 2015), que criou uma ferramenta para observação dinâmica do tráfego de veículos na cidade de Lisboa. Utilizando a metáfora do sistema circulatório, somado ao mapeamento das vias e uma base de dados com informações de tráfego ao longo do tempo, Cruz criou um sistema onde é possível, por meio de 
animação, compreender onde e quando ocorrem determinados pontos de aglomeração e dispersão de veículos na área urbana. Os pontos de aglomeração são evidenciados por diferenças de opacidade e espessura no traçado das vias. Ao mesmo tempo, a velocidade dos veículos faz com que o comprimento das linhas se contraia e expanda, gerando uma sensação dinâmica e intuitiva de um verdadeiro organismo vivo. Essas variáveis são utilizadas (juntas ou separadamente) em diferentes tipos de visualizações. Em algumas delas é possível ter a sensação de que a própria cidade se amplia em momentos de maior concentração/ lentidão de veículos e se contrai em momentos de esvaziamento de suas vias.

Figura 4 Captura de frame do vídeo com a visualização do tráfego da cidade de Lisboa, de Pedro Miguel Cruz.

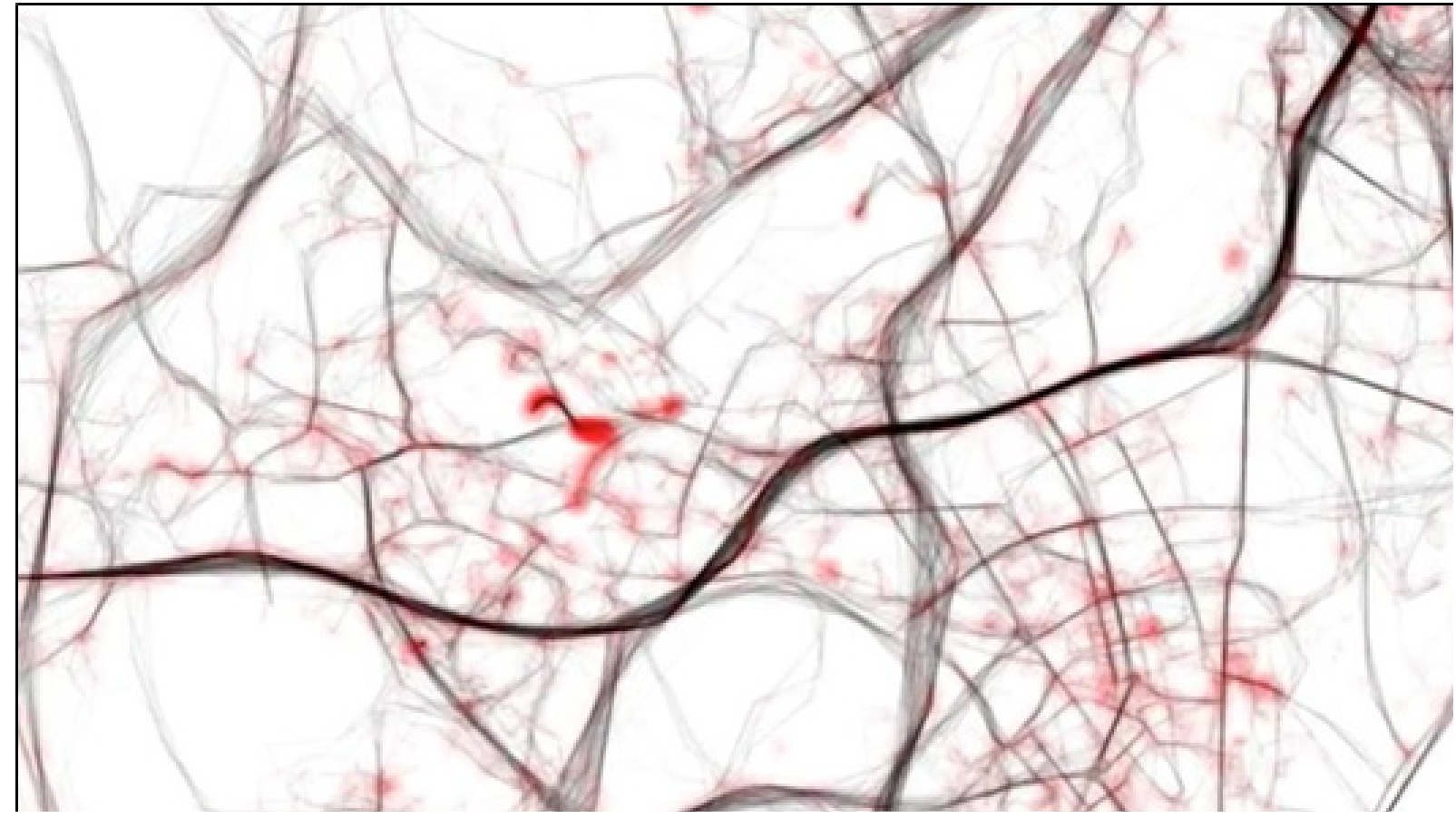

Dentro do nosso caso específico do campus de Goiabeiras, um dos objetivos da pesquisa foi identificar quais referências, elementos construídos ou elementos da natureza presentes no campus eram eleitos como marcos significativos, pontos de referência constituintes da imagem do ambiente construída por seus usuários. No que se refere a identificação desses marcos significativos, a abordagem utilizada foi fortemente influenciada pelo trabalho de Lynch (1960).

Durante o projeto, apontou-se a necessidade de conhecer o fluxo dos usuários no uso corriqueiro do espaço do campus. Através desse entendimento, seria possível identificar áreas de maior circulação e pontos de maior interesse para disposição das peças de sinalização direcionadoras. Embora tenhamos abarcado todas as formas de locomoção, esse levantamento se mostrou particularmente relevante em relação à circulação de pedestres, devido ao fato de o campus 
possuir muitos caminhos transversais previamente pavimentados, bem como outros delimitados sobre a grama a partir do uso corriqueiro de «atalhos» naturais. Dado o nível de complexidade do rizoma estabelecido, a identificação de possíveis linhas de força principais se mostrava fundamental para a construção de estratégias de direcionamento para os usuários.

Como forma de registro desse fluxo, desenvolveu-se um um mapa do campus, no qual o entrevistado era convidado a marcar com caneta o trajeto que costumava percorrer com maior frequência, a partir da entrada (Figura 5).

Figura 5 Exemplo de trajeto traçado por um usuário.

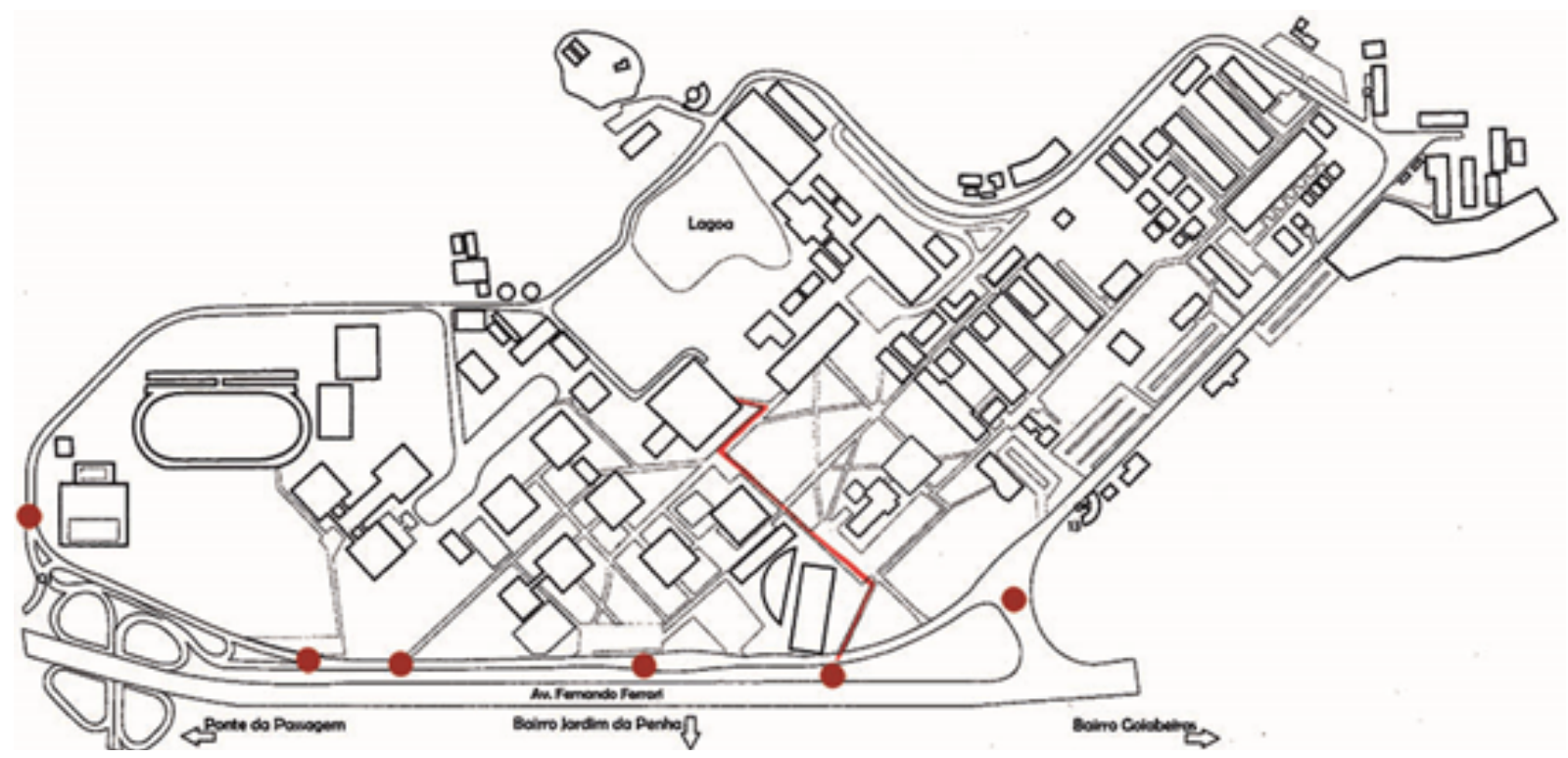

Para gerar um entendimento e análise sobre os dados recolhidos, optou-se por reunir todas as linhas de trajeto em um único mapa (Figura 6), utilizando o programa de tratamento de imagem Adobe Photoshop, separando cada traçado em uma camada diferente. 
Figura 6 Os diferentes caminhos sobrepostos mostram a complexidade do uso real do espaço.

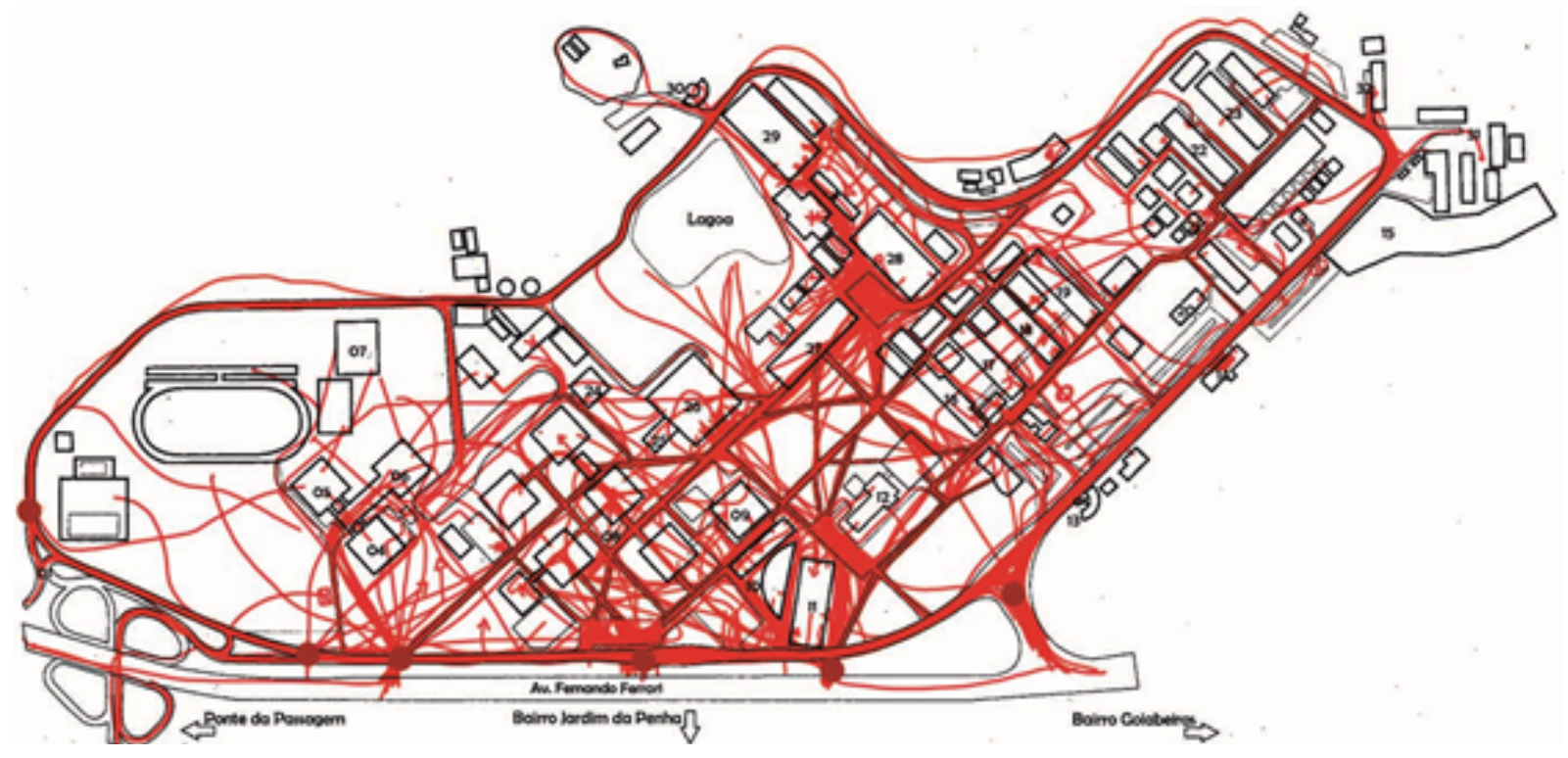

Para identificação das áreas de maior circulação de pessoas, cada trajeto (aplicado a uma camada de informação) teve sua opacidade reduzida a 2\% (Figura 7). Desse modo, trajetos semelhantes se sobrepunham, tornando a cor do traçado mais evidente em locais onde ocorriam sobreposições de caminhos individuais. Assim, utilizando camadas, foi possível identificar onde ocorriam maiores e menores incidências de fluxo de pessoas. Ao final, obteve-se um mapa de trajetos que lembra um mapa de calor, no qual os trajetos mais percorridos pela nossa amostragem contrastavam com aqueles menos percorridos.

Figura 7 Com a opacidade reduzida foi possível começar a observar trajetos de maior e menor circulação.

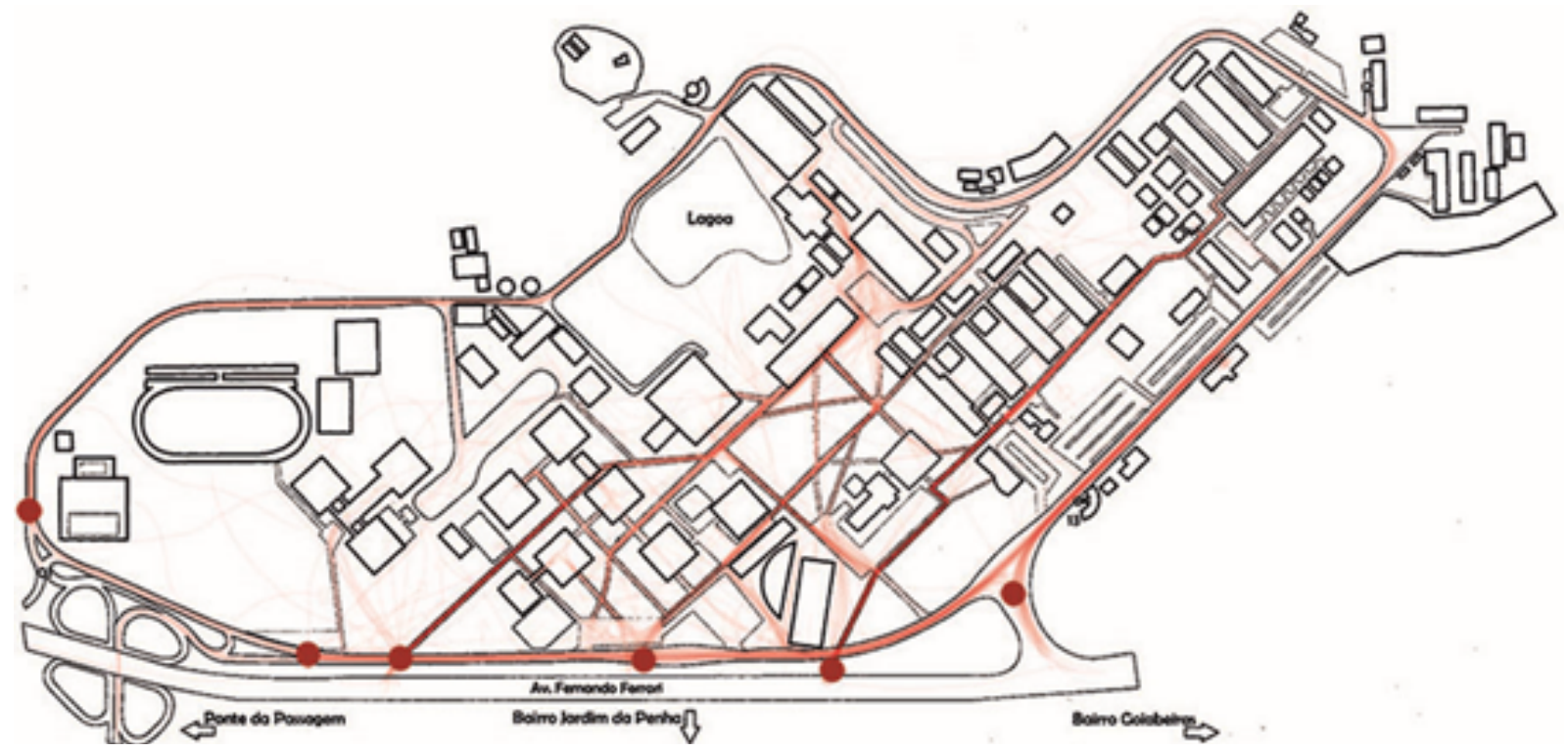


Pinheiro, M., Gomes, R. E. \& Ramos, M. R. S. | Desenhe seu trajeto: visualização de dados sobre o uso do espaço e a participação de usuários no projeto de sinalização da Universidade Federal do Espírito Santo

Figura 8 Retirando o mapa e mantendo somente a sobreposição de trajetos foi possível observar tendências predominantes, pontos de concentração e dispersão.

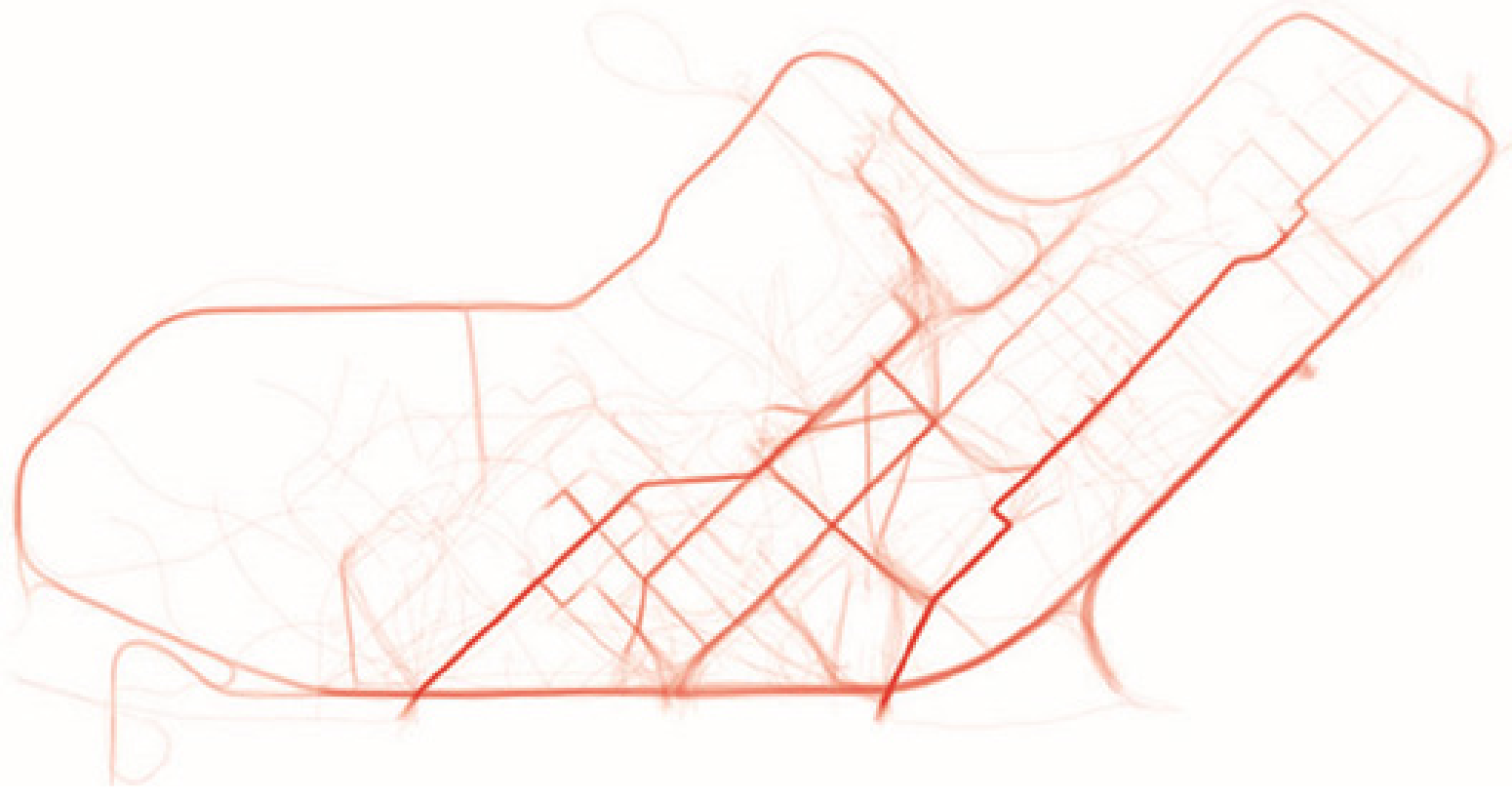

Desse modo, por meio dos gráficos gerados, pudemos identificar:

- os portões de entrada mais utilizados;

- quatro eixos principais de circulação de pessoas;

- em quais pontos desses eixos ocorrem dispersões de pessoas.

Figura 9 Principais eixos de circulação de pedestres identificados. Em vermelho, os caminhos com maior fluxo, constituindo eixos principais. Em laranja, os caminhos secundários. Em amarelo, as zonas de transição que constituem eixos terciários.

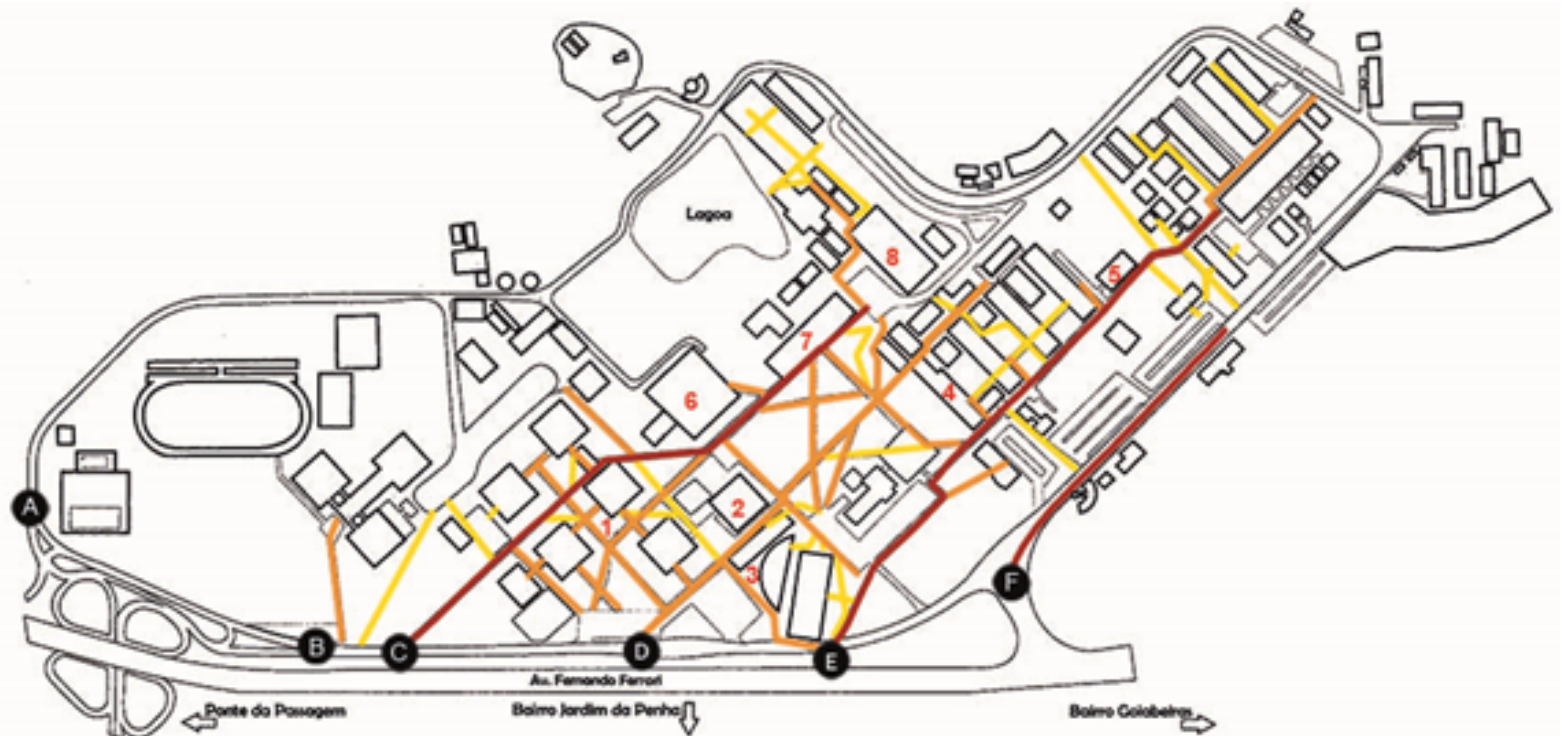


Dentre os principais caminhos identificados, pode-se notar:

1. O anel viário como trajeto principal de veículos motorizados, tendo os diferentes estacionamentos como pontos de transição entre o status de motorista e pedestre;

2. Um eixo de alta incidência de pedestres que se inicia em um dos portões (letra C, Figura 9), perpassa o Centro de Artes (1), atravessa as regiões próximas ao Restaurante Universitário (6) e Biblioteca Central (7), tendo sua principal área de dispersão na chegada ao Centro de Ciências Jurídicas e Econômicas (8);

3. Um eixo também importante, porém de menor incidência, iniciado no portão seguinte (D) e que passa pela região do Centro de Vivências e Departamento de Psicologia (3 e 2, respectivamente) em direção à região conhecida como «ICs» (4 a 5 no mapa), compreendendo o Centro de Ciências Exatas, o Centro de Ciências Humanas e Naturais e o Centro de Educação;

4. Outro eixo de alta incidência de pedestres é delimitado por uma passarela coberta que se inicia no portão subsequente (E), passa pelos prédios da Pró-Reitoria de Graduação, da Administração Central, indo em direção à citada região dos «ICs», terminando na região do Centro Tecnológico;

5. Um eixo mais curto, porém não menos importante, que se origina no portão norte de veículos e pedestres (F), passa por uma parte do anel viário, tendo seu ponto de dispersão na chegada ao prédio do Centro e Línguas, muito utilizado pela comunidade externa.

A identificação de eixos de fluxo foi fundamental para o entendimento da equipe sobre o uso do espaço, especialmente no que se refere ao trajeto de pedestres, tendo em vista que o campus é constituído por um rizoma de trajetos aparentemente confuso, à primeira vista, por sua complexidade gráfica. Com a visualização dos padrões de incidência, pudemos estabelecer estratégias de deslocamento de visitantes através desses eixos, facilitando o entendimento do espaço a partir da construção consciente de linhas mestras para o direcionamento dos visitantes.

\section{Considerações finais}

Neste projeto, desde o início buscamos uma abordagem centrada no usuário. Ao procurarmos entender como as pessoas efetivamente utilizam o espaço físico e de que maneira se referem aos locais e marcos de referência do campus, optamos por utilizar a cultura já instituída como ponto de partida para o desenvolvimento do projeto. A aplicação dos questionários, combinada com a solicitação para que os próprios usuários descrevessem e desenhassem os trajetos que costumam utilizar com mais frequência na universidade, foi uma metodologia que trouxe resultados extremante positivos, revelando padrões comportamentais 
do público da Ufes. A partir da descrição verbal dos trajetos, foi possível identificar os pontos de referência mais reconhecidos bem como os termos comumente utilizados para denominá-los. Confirmamos que a nomenclatura usada pelas pessoas nem sempre reflete a terminologia institucional - geralmente repleta de siglas e abreviações obscuras para quem não opera dentro da estrutura burocrática da universidade. Desse modo, a pesquisa foi fundamental para a definição de normas a serem utilizadas nas nomenclaturas da sinalização, privilegiando a coexistência das terminologias «oficiais» com os termos normalmente utilizados pela comunidade.

Solicitar que as pessoas desenhassem seus trajetos nos mapas mostrou-se um procedimento simples e de rápida execução, mas que evidenciou os caminhos mais utilizados, desvelando a dinâmica do deslocamento da comunidade - algo que dificilmente seria percebido com outras técnicas de pesquisa.

Nesse processo a visualização de dados foi uma ferramenta poderosa para facilitar a identificação destes fluxos e intensidade de uso dos trajetos. A partir desse mapeamento foi possível estabelecer estratégias para orientar o público, ressaltando as rotas principais e rotas secundárias. Uma vez identificados os pontos de entrada no campus (portões de acesso e estacionamentos), optamos por indicar aos usuários prioritariamente o caminho para as rotas principais, que em geral são mais diretas e cobrem uma extensão maior do campus, evitando caminhos mais complexos de difícil compreensão, mesmo que porventura estes signifiquem um deslocamento mais curto. Dessa forma, o plano de sinalização orienta os sujeitos para os caminhos mais utilizados, que abrangem diferentes regiões do campus, para posteriormente indicar acessos secundários dentro de cada região específica. Acreditamos que isso facilitará que os usuários construam a imagem do espaço (Lynch, 1960) e consigam se deslocar mais facilmente no campus.

O design centrado no usuário constitui-se assim uma abordagem de projeto «de baixo para cima», que acreditamos irá facilitar a adoção da sinalização na comunidade que frequenta a universidade, seja por parte do público interno, mas também e principalmente por parte do público externo, que, por vezes, desconhece completamente a lógica de estruturação do espaço construído. Futuros testes ainda são necessários para averiguar a eficiência do sistema projetado. Em paralelo a isso, a metodologia utilizada no campus Goiabeiras será replicada no desenvolvimento do projeto de sinalização dos demais campi da universidade, e esperamos verificar sua adequação como um procedimento a ser generalizado para outros projetos de natureza semelhante. 


\section{Referências}

ABRAS, Chadia; MALONEY-KRICHMAR, Diane; PREECE, Jenny. 2004. UserCentered Design. In: BAINBRIDGE, W. Encyclopedia of Human-Computer Interaction. Thousand Oaks: Sage Publications.

BROWN, Tim. 2010. Design thinking: uma metodologia poderosa para decretar o fim das velhas ideias. Rio de Janeiro: Elsevier.

CRUZ, Pedro Miguel. Lisbon's blood vessels: a cartogram and a metaphor. <http:// pmcruz.com/information-visualization/lisbons-blood-vessels>, 16/03/2015.

CHAVES, Iana G.; BITTENCOURT, João Paulo; TARALLI, Cibele H. 2013. O Design centrado no humano na atual pesquisa brasileira: uma análise através das perspectivas de Klaus Krippendorf e da Ideo. Holos, Ano 29, v.6, pp. 213225, 2013. Natal.

DAL BIANCO, Bianca; DAMAZIO, Vera (Orientadora). Design em parceria: reflexões sobre um modo singular de projetar sob a ótica do Design e Emoção. Rio de Janeiro, 2007. Dissertação de mestrado - Departamento de Artes e Design, Pontifícia Universidade Católica do Rio de Janeiro.

GARRET, Jesse James. 2011. The Elements of User Experience: user centered design for the web and beyond. 2. ed. Berkeley: New Riders.

LYNCH, Kevin. 1960. The image of the city. Cambridge: MIT Press.

KRIPPENDORFF, Klaus. 2000. Design centrado no usuário: uma necessidade cultural. Estudos em Design, v. 8, no 3. Rio de Janeiro.

PINHEIRO, Mauro, et al. 2006. Sinalização e ambientação da Pró-Reitoria de Graduação da Universidade Federal do Espírito Santo. In: Congresso Brasileiro de Pesquisa e Desenvolvimento em Design (P\&D Design), 7., 2006, Curitiba. Anais...CD-ROM. Curitiba.

ROCHA, Mariane A.; GARONE, Priscilla. M. Cardoso. 2014. Infografia na sinalização: o design da informação e os serviços oferecidos pela Universidade Federal do Espírito Santo aos ingressantes do campus de Goiabeiras. In: ERGODESIGN-USIHC 2014, 2014, Joinville. Anais....meio digital. Joinville.

WINOGRAD, Terry.; KUHN, Sarah. 1996. Participatory Design. In: WINOGRAD, Terry. Bringing design to software. Stanford: Stanford University. <http://hci. stanford.edu/publications/bds/14-p-partic.html>, 16/032015.

VIANNA, Maurício, et al. 2012. Design thinking: inovação em negócios. Rio de Janeiro: MJV Press.

TUFTE, Edward. 1997. Visual Explanations: images and quantities, evidence and narrative. Cheshire: Graphis Press. 
Pinheiro, M., Gomes, R. E. \& Ramos, M. R. S. | Desenhe seu trajeto: visualização de dados sobre o uso do espaço e a participação de usuários no projeto de sinalização da Universidade Federal do Espírito Santo

\section{Sobre os autores}

\section{Mauro Pinheiro,}

Dr. Ufes / Esdi-Uerj, Brasil <mauro.pinheiro@gmail.com>

\section{Ricardo Esteves Gomes,}

Msc. Ufes, Brasil < ricardo@ladht.com>

Matheus Rocha de Souza Ramos,

Bacharel, Ufes, Brasil <matheusrochasr@gmail.com

Artigo recebido em 09 set. 2015,

aprovado em 21 set. 2015. 